\title{
COVID-19, Brachytherapy, and Gynecologic Cancers: a Moroccan Experience
}

\author{
Sanaa EIMajjaoui ${ }^{1}$ (D) $\cdot$ Nabil Ismaili $^{2} \cdot$ Noureddine Benjaafar $^{1}$
}

Accepted: 8 July 2020 / Published online: 15 July 2020

(C) Springer Nature Switzerland AG 2020

\begin{abstract}
The treatment of gynecological cancers is the main activity of brachytherapy units. However, during COVID-19 pandemic, precautions should be done in order to reduce the spread of the virus while maintaining all chances to recovery for all patients (Radiother Oncol 148, 227-228, 2020). Despite the extent of the pandemic in our country, limited data are available to establish recommendations with a sufficient level of evidence (Radiother Oncol 148, 227-228, 2020). More recently, the American Brachytherapy Society published some clarifications in this regard and international expert consensus recommendations of radiation therapy for gynecologic malignancies during the COVID-19 pandemic were published (https:// www.americanbrachytherapy.org/about-abs/abs-news/abs-statement-on-coronavirus/, Gynecol Oncol 15, 2020). In this commentary, we sought to share the procedures adopted for the management of gynecological cancer patients during COVID-19 pandemic in our brachytherapy unit.
\end{abstract}

Keywords COVID-19 $\cdot$ Brachytherapy $\cdot$ Cervical cancer $\cdot$ Endometrial cancer $\cdot$ Vaginal cancer

\section{Dear Editor,}

The treatment of gynecological cancers is the main activity of brachytherapy units. However, during COVID-19 pandemic, precautions should be done in order to reduce the spread of the virus while maintaining all chances to recovery for all patients [1].

Among all these precautions are as follows:

- Management of cancer patients should be done in "COVID-19 negative" units, excluding all suspected cases waiting for COVID-19 test results.

This article is part of the Topical Collection on Covid-19

Sanaa ElMajjaoui

drsanaamajjaoui@hotmail.com

Nabil Ismaili

ismailinabil@yahoo.fr

Noureddine Benjaafar

benjaafar@menara.ma

1 Department of Radiotherapy, National Institute of Oncology, Mohammed V University, Rabat, Morocco

2 Department of Medical Oncology, Cheick Khalifa International University Hospital, Mohammed VI University of Health Sciences (UM6SS), Casablanca, Morocco
- Establish a circuit dedicated for patients suspected with COVID-19 infection.

- Reduce the number of patients by establishing priority lists to limit risk of exposure with other patients and staff.

- Limit the number of patients waiting for brachytherapy consultations, in the waiting room.

- Monitor patients at admission to brachytherapy unit, for symptoms suggestive of COVID 19 infection: fever, cough, or dyspnea. Take their temperature.

- Prohibit accompanying persons to access the service whenever possible.

- Patients and staff should wear protective masks.

- In order to maintain a sufficient distance between patients, reduce the number of hospitalization in brachytherapy unit (one patient per room).

Despite the extent of the pandemic in our country, limited data are available to establish recommendations with a sufficient level of evidence [1]. More recently, the American Brachytherapy Society published some clarifications in this regard and international expert consensus recommendations of radiation therapy for gynecologic malignancies during the COVID-19 pandemic were published [2, 3]. In this commentary, we sought to share the procedures adopted for the management of gynecological cancer patients during COVID-19 pandemic in our brachytherapy unit. 
Cervical cancer is the most common gynecological cancer in our country. In the majority of cases, the treatment is based on EBRT (exclusive in early stages and with concurrent chemotherapy in locally advanced stages), followed by intracavitary brachytherapy (ICBT) which constitutes a cornerstone in its management [4]. Brachytherapy is one of the radiotherapy techniques offering the most interesting therapeutic index by delivering high doses in a very conformational way. However, omission of brachytherapy results in important reduction in the curative potential of treatment [5]. The development of high-dose rate brachytherapy guided by imaging, as well as endo-cavitary and interstitial hybrid techniques and dose escalation strategies [6], has contributed more in improving local control and overall survival (OS) while reducing rate of late urinary, intestinal, and gynecological toxicities [7-9]. Technical advances in EBRT (IMRT, VMAT, and stereotaxic radiotherapy) have led to replacing brachytherapy boost by RT boost [10, 11]. However, local control, progression-free survival (PFS), and safety were significantly better with brachytherapy [12-16]. Therefore, ICBT boost remains the procedure of choice. Brachytherapy should be delivered immediately after EBRT. Longer treatment duration has been shown to be a worse prognostic factor for local control (an overall duration of treatment that exceeds 56 days results in a loss of $1 \%$ of local control per day) [17-22]. This encourages us to respect as much as possible the time between EBRT and brachytherapy. Therefore, there are no major changes in brachytherapy procedures for patients with cervical cancers. However, to minimize the risk of contamination, precautionary measures have been implemented:

- Prefer the schemes with a reduced number of fractions: $3 \times 8$ Gy or $4 \times 7$ Gy. In our unit, we use the HDR ICBT schedule of 7 Gy per fraction for 4 fractions in 2 insertions 1 week apart. For each insertion, the patients receive 2 fractions per day separated by a 6 -h interval $[3,17]$. For patients over 70 years of age or with significant comorbidities (chronic respiratory or cardiac pathology, immunosuppression, etc.) who have small tumors or responding well to external beam radiotherapy (EBRT), a more shortened schedule of 9 Gy per fraction in 2 fractions at 1 week apart may be considered. [23, 24]

- The brachytherapy program is adapted by limiting number of patients hospitalized, without compromising the treatment time duration.

Patients without COVID-19 symptoms, who have already started their ICBT, should complete their schedule without delay. Under normal conditions, all ICBT applications are done using spinal anesthesia and ultrasound guidance; however, the concern during covid-19 pandemic is the lack of anesthesiologist and their staff [17]. In this case, we may consider pudendal nerve block or local anesthesia by paracervical block, or by the use of medical hypnosis technique [17]. If all of these tools are not available, consider to insert applicator with uterine tandem which diameter not exceeding $4 \mathrm{~mm}$, without anesthesia. For COVID-19-positive patient, delivering ICBT on time is recommended. However, in our department, as well as in other centers, we have only one brachytherapy operating room and a single bunker. Therefore, treatment should be postponed for at least 24 days or until the infection is resolved.

For patients with early endometrial cancer, surgical treatment remains the standard of care. Adjuvant treatment by EBRT and/or brachytherapy is recommended according to the prognostic factors in the anatomopathological report. Vaginal vault brachytherapy (VVB) is recommended in intermediate risk endometrial cancer. It significantly reduces the rate of vaginal relapse. However, there is no significant difference in terms of long-term relapse, DFS, or OS [25, 26]. Consequently, delaying VVB may be appropriate for this risk group. In the setting of COVID-19 outbreak, we suggest postponing brachytherapy up to 12 weeks [3]. For patients with significant comorbidities, exposing them to the risk of severe complications of COVID-19 infection (old age, chronic respiratory or cardiac diseases, immunosuppression, etc.), it may be judicious to delay brachytherapy for 6 months. For patients who should start VVB, consider the schedule of 7 Gy for 3fractions to a depth dose of $0.5 \mathrm{~cm}$, to limit the number of patient displacement. An interval spacing of 14 days between the fractions is also acceptable. However, for high-risk patients who received adjuvant external RT, omitting BVV may be reasonable because of no evidence for combining of RT and VVB (except in the case of positive margins) [2, 17]. For stage II endometrial cancers, adjuvant VVB is delivered exclusively (if invasion $<50 \%$ of the myometrium, G1 and 2) or after EBRT (if invasion $>50 \%$ of the myometrium, G3). In both cases, consider to postpone brachytherapy by 1 to 2 months. In the case of a COVID-19 positive patient, postpone treatment for at least 24 days [2].

For early vaginal cancer (stage I, $<5 \mathrm{~mm}$ of invasion), exclusive brachytherapy is the treatment of choice with EQD2 of 60-75 Gy to the tumor with $2 \mathrm{~cm}$ margin (7 Gy for 5 fractions) [3]. In patients with significant comorbidities (old age, chronic respiratory pathology or cardiac, immunosuppression ...), consider to postpone brachytherapy by 1 to 2 months. For advanced stage, which represent the vast majority of cases, consider radio(chemotherapy) treatment followed by vaginal brachytherapy (7 Gy for 3 fractions) [3]. Brachytherapy treatment should be started on time without any delay.

Prioritization list in gynecological brachytherapy:

- Priority 1: Brachytherapy is the curative treatment:

- Brachytherapy for cervical cancer (stage IB1, IIIB). 
- Brachytherapy for vaginal cancer (stage I, $<5 \mathrm{~mm}$ of invasion, locally advanced stage).

- Priority 2: Brachytherapy is the exclusive adjuvant treatment:

- Brachytherapy for stage I intermediate risk endometrial cancer.

- Brachytherapy for stage II endometrial cancer without poor prognostic factors (invasion $<50 \%$ of the myometrium, G1 and 2).

- Priority 3: Adjuvant treatment is based on radiotherapy and brachytherapy:

- Brachytherapy for stage II endometrial cancer with poor prognostic factors (if invasion $>50 \%$ of the myometrium, G3).

- Brachytherapy for stage I high-risk endometrial cancer.

Contributors All authors contributed to the conception and design, drafting, and critical revision of this manuscript. All authors have given final approval of this version to be published, and all authors accept responsibility for its contents.

\section{Compliance with Ethical Standards}

Conflict of Interest The authors declare that they have no conflict of interest.

Ethical Approval This article does not contain any studies with human participants performed by any of the authors.

Disclosures The authors declare that there is no source of support in the form of grants, bursaries, free use of equipment, drugs or any other benefits to disclose.

\section{References}

1. Ismaili N. COVID-19 and gynecological cancers: a Moroccan point-of-view. Radiother Oncol. 2020;148:227-8.

2. https://www.americanbrachytherapy.org/about-abs/abs-news/absstatement-on-coronavirus/

3. Elledge CR, Beriwal S, Chargari C, Chopra S, Erickson BA, Gaffney DK, et al. Radiation therapy for gynecologic malignancies during the COVID-19 pandemic: international expert consensus recommendations. Gynecol Oncol. 2020;15 S00908258(20)32301-5.

4. Elmajjaoui S, Ismaili N, El Kacemi H, Kebdani T, Sifat H, Benjaafar N. Epidemiology and outcome of cervical cancer in national institute of Morocco. BMC Womens Health. 2016;16(1):62. https://doi.org/10.1186/s12905-016-0342-2.

5. Logsdon MD, Eifel PJ. FIGO IIIB squamous cell carci- noma of the cervix: an analysis of prognostic factors emphasizing the balance between external beam and intracavitary radiation therapy. Int $\mathrm{J}$ Radiat Oncol Biol Phys. 1999;43:763-75.

6. Cetina L, González-Enciso A, Cantú D, Coronel J, Pérez-Montiel D, Hinojosa J, et al. Brachytherapy versus radical hysterectomy after external beam chemoradiation with gemcitabine plus cisplatin: a randomized, phase III study in IB2-IIB cervical cancer patients. Ann Oncol. 2013;24:2043-7.
7. Pötter R, Dimopoulos J, Georg P, Lang S, Waldhäusl C, WachterGerstner N, et al. Clinical impact of MRI assisted dose volume adaptation and dose esca- lation in brachytherapy of locally advanced cervix cancer. Radiother Oncol. 2007;83:148-55.

8. Lindegaard JC, Fokdal LU, Nielsen SK, Juul-Christensen J, Tanderup K. MRI- guided adaptive radiotherapy in locally advanced cervical cancer from a Nordic perspective. Acta Oncol. 2013;52:1510-9.

9. SturdzaA, PötterR, FokdalLU, Haie-MederC, TanLT, MazeronR, etal. Image guided brachytherapy in locally advanced cervical cancer: improved pelvic control and survival in RetroEMBRACE, a multicenter cohort study. Radiother Oncol 2016;120:428-433.

10. Logsdon MD, Eifel PJ. Figo IIIB squamous cell carcinoma of the cervix: an analysis of prog- nostic factors emphasizing the balance between external beam and intracavitary radiation therapy. Int $\mathbf{J}$ Radiat Oncol Biol Phys. 1999;43:763-75.

11. Karlsson J, Dreifaldt A-C, Mordhorst LB, Sorbe B. Differences in outcome for cervical cancer patients treated with or without brachyther- apy. Brachytherapy. 2017;16(1):133-40 [Epub 2016].

12. Georg D, Kirisits C, Hillbrand M, Dimopoulos J, Pötter R. Imageguided radiotherapy for cervix cancer: high-tech external beam ther- apy versus high-tech brachytherapy. Int J Radiat Oncol Biol Phys. 2008;71:1272-8.

13. Sturdza A, Pötter R, Fokdal LU, Haie-Meder C, Tan LT, Mazeron $\mathrm{R}$, et al. Image guided brachytherapy in locally advanced cervical cancer: improved pelvic control and survival in RetroEMBRACE, a multicenter cohort study. Radiother Oncol. 2016;120:428-33.

14. Haie-Meder C, Pötter R, Van Limbergen E, Briot E, De Brabandere M, Dimopoulos J, et al. Recommendations from Gynaecological (GYN) GEC-ESTRO Working Group (I): concepts and terms in 3D image based 3D treatment planning in cervix cancer brachytherapy with emphasis on MRI assessment of GTV and CTV. Radiother Oncol. 2005;74:235-45.

15. Pötter R, Haie-Meder C, Van Limbergen E, Barillot I, De Brabandere M, Dimopoulos J, et al. Recommendations from gynaecological (GYN) GEC ESTRO working grooooup (II): concepts and terms in 3D image-based treatment planning in cervix cancer brachytherapy-3D dose volume parameters and aspects of 3D image-based anatomy, radiation physics, radiobiology. Radiother Oncol. 2006;78:67-77.

16. Viswanathan AN, Dimopoulos J, Kirisits C, Berger D, Pötter R. Computed tomography versus magnetic resonance imaging-based contouring in cervical cancer brachytherapy: results of a prospective trial and preliminary guidelines for standardized contours. Int $\mathrm{J}$ Radiat Oncol Biol Phys. 2007;68:491-8.

17. Williams VM, Kahn JM, Harkenrider MM, Chino J, Chen J, et al. COVID-19 impact on timing of brachytherapy treatment and strategies for risk mitigation. Brachytherapy. 2020;21 S15384721(20)30079-9.

18. Radiation Therapy Oncology Group. RTOG 0417. A phase II study of bevacizumab in combination with definitive radiother- apy and cisplatin chemotherapy in untreated patients with locally advanced cervical carcinoma. http://www.rtog.org/ClinicalTrials/ ProtocolTable/StudyDetails.aspx?study $1 / 40417$.

19. National Cancer Institute, Clinical Trials (PDQVR ). Phase III randomized study of cisplatin and radiotherapy with versus without tirapazamine in patients with stage IB, IIA, IIB, IIIB, or IVA carcinoma of the cervix.http://cancer.gov/clinicaltrials/search/ view? cdrid1/4455555\&version1/4healthprofessional.

20. Atahan IL, Onal C, Ozyar E, Yiliz F, Selek U, Kose F. Long-term outcome and prognostic factors in patients with cervical carcinoma: a retrospective study. Int J Gynecol Cancer. 2007;17:833-42.

21. Song S, Rudra S, Hasselle MD, Dorn PL, Mell LK, Mundt AJ, et al. The effect of treatment time in locally advanced cervical cancer in the era of concurrent chemoradiotherapy. Cancer. 2013;119:32531. https://doi.org/10.1002/cncr.27652. 
22. Mazeron R, Castelnau-Marchand P, Dumas I, del Campo ER, Kom LK, Martinetti F, et al. Impact of treatment time and dose escalation on local control in locally advanced cervical cancer treated by chemoradiation and image-guided pulsed-dose rate adaptive brachytherapy. Radiother Oncol. 2015;114:257-63. https://doi.org/10. 1016/j.radonc.2014.11.045.

23. Patel FD, Rai B, Mallick I, Sharma SC. High-dose-rate brachytherapy in uterine cervical carcinoma. Int J Radiat Oncol Biol Phys. 2005;62(1):125-30.

24. Novetsky AP, Einstein MH, Goldberg GL, Hailpern SM, Landau E, Fields AL, et al. Efficacy and toxicity of concomitant cisplatin with external beam pelvic radiotherapy and two high-dose-rate brachytherapy insertions for the treatment of locally advanced cervical cancer. Gynecol Oncol. 2007;105(3):635-40 Epub 2007 Feb 27.
25. Sorbe B, Nordström B, Mäenpää J, Kuhelj J, Kuhelj D, Okkan S, et al. Intravaginal brachytherapy in FIGO stage I low-risk endometrial cancer: a controlled randomized study. J Int Gynecol Cancer. 2009;19:873-8.

26. Nout R, Smit V, Putter H, Jürgenliemk-Schulz I, Jobsen J, Lutgens LCHW, et al. Vaginal brachytherapyversus pelvic external beam radiotherapy for patients with endometrial cancer of highintermediate risk (PORTEC-2): an open-label, non-inferiority, randomised trial. Lancet. 2010;375:816-23.

Publisher's Note Springer Nature remains neutral with regard to jurisdictional claims in published maps and institutional affiliations. 